\title{
REVIEW
}

\section{Assessing mood in older adults: a conceptual review of methods and approaches}

\author{
Laura J. E. Brown ${ }^{1}$ and Arlene J. Astell ${ }^{2}$ \\ ${ }^{1}$ Department of Psychology, Manchester Metropolitan University, Manchester, UK \\ ${ }^{2}$ School of Psychology, University of St Andrews, St Andrews, UK
}

ABSTRACT

Background: Accurate measures of mood state are important for understanding and optimizing health and well-being in later life. A range of different mood assessment measures is available, reflecting the variety of ways in which mood has been conceptualized and the different purposes for which measures have been developed.

Methods: We undertook a conceptual review of the literature relating to mood and its assessment in older populations.

Results: Moods are subjective states of mind that are typically described and quantified using self-report measures. Moods can be conceptually differentiated from the related psychological concepts of emotion, wellbeing, quality of life, and depression. Quantitative tools for assessing mood state include single-item mood ratings, composite factor scales, and clinical depression assessments. Mood assessments may be administered retrospectively or contemporaneously to the mood state of interest. The method and temporal perspective used to assess mood state will impact on the nature and precision of the mood data that are collected, and the types of research questions that can be addressed.

Conclusions: No single mood assessment technique can be considered optimal for all situations. Rather, both the type of tool and the temporal perspective taken must be selected according to the nature of the study design and the research question being addressed. More thorough and frank reporting of the rationale for, and limitations of, mood assessment techniques are also essential for continued development of mood research with older adults.

Key words: affect, happiness, mental health, aging, quality of life, depression

\section{Introduction}

It is well documented that clinical mood disorders such as depression have negative effects on the physical, social, and mental functioning of older adults. However, non-clinical patterns of mood state, that is everyday mood in the general population, also have important associations with health and well-being. For instance, mood states in healthy adult populations have been associated with biological indicators of health such as blood pressure and cortisol levels (Steptoe and Wardle, 2005) and somatic symptoms such as poor appetite and stomach upsets (Charles and Almeida, 2006),

Correspondence should be addressed to: Dr. Arlene J. Astell, School of Psychology, University of St Andrews, St Andrews, UK. Phone: +44 1334 462056; Fax: +44 1334 463042. Email: aja3@st-and.ac.uk. Received 9 Sep 2011; revision requested 14 Dec 2011; revised version received 5 Jan 2012; accepted 10 Jan 2012. First published online 20 February 2012. as well as health-related behaviors such as exercise (Powell et al., 2009) eating habits (Konttinen et al., 2010), and patterns of cognitive ability (Hill et al., 2005). Mood states also color and shape our subjective mental experiences and fundamentally contribute to levels of happiness (Diener, 2000) and quality of life (Kelley-Gillespie, 2009). In this regard, older adults generally report higher levels of positive affect and lower levels of negative affect than younger adults (e.g. Stawski et al., 2008), a finding which is consistent across cultures (Fischer, 2009). This highlights the importance of being able to accurately and sensitively measure and understand mood patterns in later life.

There are a number of key issues surrounding mood assessment methods that have an impact on the nature and quality of the information collected. These include the pervasiveness of selfreport measures, the number of items used to 
assess each mood construct, and the temporal perspective that individuals are asked to adopt when considering their mood. The way that mood is conceptualized and differentiated from related psychological phenomena such as emotion, depression, well-being, and quality of life also has important implications for the selection and interpretation of mood assessments. A thorough understanding of the issues surrounding mood assessment is therefore essential when either selecting tools to use with older populations or when appraising and interpreting mood research data. Here, we provide a conceptual overview of some of the key issues relating to mood constructs and their measurement, and discuss the implications of these for assessing mood in older populations.

\section{An overview of mood state}

Moods are the affective "states of mind" that underlie our subjective mental life. They are a fundamental component of day-to-day experience, and can influence our perceptions of, and interactions with, the world. The biological causes and correlates of mood states are only just beginning to be understood (Urry et al., 2004). Accordingly, most of our knowledge about the nature and content of mood experiences has been determined through introspection and subjective report.

Moods are typically conceptualized as dimensions on which people can be located. At the broadest level, these dimensions reflect the levels of positive and negative content of a person's affective experience. For instance, high levels of positive affect are related to feelings of energy, concentration and pleasurable engagement, whereas low levels of positive affect are associated with feelings of sadness or lethargy. People who experience high levels of negative affect report feelings such as distress and lack of pleasurable engagement, whereas low negative affect is typified by feelings of calmness and serenity (Watson and Clark, 1994). The dimensions of positive and negative mood appear to be somewhat independent from one another (Watson and Tellegen, 1985), meaning that it is possible to experience aspects of positive and negative mood at the same time (Larsen et al., 2001). The balance between the amount of positive and negative affect experienced at any one time is considered by some researchers to represent an individual's overall level of "happiness" (Diener, 2000). However, somewhat confusingly, the term "happiness" is also sometimes used to describe purely positive aspects of mood (e.g. Watson and Clark, 1994).

Patterns of mood can be described both at the level of relatively transient "states" and more stable "traits". Mood traits are akin to personality characteristics. They are at least partly genetically determined (Lykken and Tellegen, 1996), and appear to remain relatively stable across the lifespan (Costa et al., 1987). Mood traits can be conceptualized as reflecting both the capacity and the tendency of an individual to experience particular positive or negative moods (Petersen, 2006). Thus, someone with low levels of trait positive affect would be more likely to experience states of sadness and lethargy than someone with a higher level of trait positive affect. Despite these characteristic patterns of mood trait, an individual's mood state will show considerable variation over time (Röcke et al., 2009). Patterns of mood state are therefore particularly relevant to interventions that aim to optimize health and well-being later in life.

\section{Mood and emotion}

Like mood states, emotions are also conceptualized as transient states of affective experience (Watson and Clark, 1997), and can be described using much of the same vocabulary. For instance, one can talk of having an anxious emotional experience or of being in an anxious mood (Beedie et al., 2011). Beedie et al. (2005) reviewed academic and lay descriptions of the differences between emotions and mood states in order to determine the key features that seemed to differentiate them. They found that emotions are generally considered to be briefer, more intense experiences than moods, and to be more closely associated with distinct physiological responses. Emotional experiences are also more likely than moods to be associated with consciously identifiable sensory stimuli, such as a frightening noise or a hurtful remark. In contrast, moods were considered to be relatively diffuse experiences that often cannot be attributed to a clear causal stimulus - we may just wake up feeling blue some days without a clear understanding why. However, despite this apparently clear conceptual distinction between moods and emotions, in practice it may not always be possible to distinguish between the two (Beedie et al., 2011). Furthermore, the extent to which moods and emotions differ in terms of their effects on health, well-being, and behavior, and thus need to be distinguished in assessment and research, is not yet known.

\section{Well-being and quality of life}

Mood states are also related to the broader psychological concepts of well-being and quality of life. Academic definitions of the term "wellbeing" tend to be somewhat loose and inconsistent. Nevertheless, there is an emerging consensus that at least two distinct aspects of mental well-being can be identified: "subjective" (or hedonic) wellbeing, and "psychological" (or eudaimonic) wellbeing (Ryan and Deci, 2001). The concept of 
subjective well-being is of most relevance to mood states. It has been defined as representing a combination of: (1) cognitive judgments regarding general satisfaction with life, and (2) the overall balance between positive and negative moods, or "happiness" (Diener, 2000).

This definition of subjective well-being can be psychometrically distinguished from the more existential phenomenon of psychological well-being (Linley et al., 2009), which includes measures of one's positive relations with others, selfacceptance, purpose in life, autonomy, growth, and mastery (Ryff, 1995). This divergence in conceptualization of well-being means that some well-being measurement tools (e.g. The WarwickEdinburgh Mental Well-being Scale of Tennant et al., 2007) incorporate items that are directly related to mood state, whereas others (e.g. the wellbeing scale developed by Ryff and Keyes, 1995) do not.

"Quality of life" is another term related to mood states that has been differentially defined and operationalized by researchers. In a recent review of the literature, Kelley-Gillespie (2009) concluded that the concept of quality of life could be broken down into six core life domains: social, physical, spiritual, environmental, cognitive, and psychological. Within this framework, mood states are important contributors to the psychological domain of quality of life (Kelley-Gillespie, 2009). Some measures relating to psychological quality of life may therefore include items that are of relevance to mood state.

\section{Mood and depression}

Depression is a clinical mood disorder characterized by a constellation of cognitive, behavioral, and affective symptoms (see Table 1). One of the

Table 1. Symptoms of major depressive episode in ICD-10 and DSM-IV
Depressed mood for two weeks
Loss of interest (anhedonia)
Fatigue or decreased energy
Loss of confidence or self-esteem
5 Self-reproach or guilt
6 Recurrent thoughts of death, suicide, or suicidal behavior
7 Diminished concentration or indecisiveness
8 Agitation or retardation
9 Sleep disturbance
10 Appetite and weight change

In the DSM-IV, five symptoms (including either number 1 or 2 ) are required for a diagnosis of major depression. In the ICD-10, eight symptoms (including two of 1,2 , or 3 ) are required for a diagnosis of severe depression; six symptoms (including two of 1 , 2 , or 3) for moderate depression; and four symptoms (including two of 1,2 , or 3 ) for mild depression. defining features of depression is the presence of a prolonged period of depressed mood. This marks depression out as different from the normal fluctuations in mood state that an individual might typically experience in the course of a day or week. Clinically significant depressed mood also interferes with an individual's everyday functioning to the extent that they may not be able to fulfill their social roles or carry out activities of daily living. Depression can therefore be understood as an extreme negative mood state that is distinguishable from the everyday mood experienced by nondepressed people.

\section{Methods of assessing mood}

Most methods of mood assessment require participants to consider and report the content of their own subjective mood experiences. This may be achieved by presenting participants with specific mood descriptors, and asking them to quantify their own level of this feeling on a standardized response scale. For instance, participants might be asked to rate the extent to which they feel "happy," "at ease," or "angry at self" (Watson and Clark, 1994). Alternatively, pictograms of faces bearing particular expressions can be used to represent the corresponding mood state (e.g. Stern et al., 1997).

\section{The challenges of mood assessment}

Self-report methods of mood assessment share many of the issues and drawbacks associated with self-report measures in other domains. Most notably, they depend on a participant's ability and willingness to perceive and report accurately the subjective states that they experience. The subjective nature of mood descriptors and phenomena means that self-report methods are particularly vulnerable to individual differences in the way that terms are interpreted or understood. For instance, commonly used terms such as "happiness" or "sadness" may not mean the same thing to all participants, particularly when considering groups who are dissimilar in terms of age, culture, or socioeconomic status. Similarly, the baseline reference frames against which people judge their current mood state may also differ between people (cf. Robertson et al., 2009). Apparent differences in reported mood state may therefore, in some cases, actually represent variations in the way that terms have been understood or evaluated rather than in the way that the mood states were actually experienced. In the absence of objective markers of mood state, the extent of such threats to the validity of the mood assessment measures are difficult to determine. 
Assessing mood in older adults presents additional challenges to the reliability and validity of data collection compared to when working with younger populations. For instance, the increased prevalence of physical or sensory impairments may affect the ease with which particular procedures can be followed. Older individuals who are frailer may also tire more easily, making the use of more time-consuming procedures impractical. Computerized presentation has the potential to reduce respondent burden (Gardner et al., 2004), particularly if the system uses an adaptive approach to reduce the number of items (Fliege et al., 2005) but at present there are no such measures available for mood assessment, only depression (Gardner et al., 2004). Impairments of memory and other cognitive functions can also limit compliance with, or understanding of, relatively complex procedures involved in mood assessment in older adults. Specialist mood assessment measures, such as the Dementia Mood Assessment Scale (Sunderland et al., 1988) are available, but have limited applicability to non-clinical groups. Finding measures that are suitable for studies that include both clinical and non-clinical populations may therefore prove challenging.

Careful selection of assessment tools is clearly essential to ensure that they are suitable for all members of the target population, and that the reliability of data will not be systematically compromised through poor compliance. When judging the suitability of a particular tool, researchers should ensure that acceptable levels of tolerance and reliability have been established in their target population. Where such data are not available, a thorough pilot study should be carried out to ensure any potential problems are identified and resolved.

\section{Mood scales}

A number of self-report tools for measuring mood states in non-clinical populations have been developed. These include single-item measures, in which facets of mood are quantified on the basis of a response to just one question, and composite factor scales, in which moods are described according to the sum of responses given to a particular subset of items. As an example, a single-item measure of "happiness" would be obtained by simply asking the participant to rate how happy they feel (e.g. Abdel-Khalek, 2006). In contrast, in a factor scale, participants' responses to a set of related items (such as how "happy," "joyful," "delighted," "cheerful," "excited," "enthusiastic," "lively," and "energetic" they feel) are summed to produce a measure of a unifying mood facet, such as "joviality" (Watson and Clark, 1994).

Higher-order facets of mood can also be measured by summing participants' responses to a broader range of terms. Table 2 details some of the more commonly used factor mood scales,

Table 2. Details of the contents of some common factor scales of mood

\begin{tabular}{|c|c|}
\hline SCALE & DESCRIPTION \\
\hline $\begin{array}{l}\text { Positive and Negative } \\
\text { Affect Schedule } \\
\text { (PANAS). (Watson } \\
\text { et al., 1988) }\end{array}$ & $\begin{array}{l}\text { A } 20 \text {-item scale that measures two mood factors: positive affect (defined by ten items), and } \\
\text { negative affect (ten items). Each item is an adjective that describes a facet of mood state (e.g. } \\
\text { "interested" or "upset"). Participants respond to each item on a 5-point scale ranging from } \\
\text { "very slightly or not at all" to "extremely", according to the extent to which they have felt that } \\
\text { way in the stated time period. }\end{array}$ \\
\hline $\begin{array}{l}\text { PANAS-X (Watson } \\
\text { and Clark, 1994) }\end{array}$ & $\begin{array}{l}\text { An extended version of the PANAS that contains the original } 20 \text { items plus } 40 \text { additional items. } \\
\text { Positive and negative affects are measured using the same items as in PANAS. Eleven more } \\
\text { specific affects are also assessed. These are: fear (defined by six items), sadness (five items), } \\
\text { guilt (six items), hostility (six items), shyness (four items), fatigue (four items), surprise (three } \\
\text { items), joviality (eight items), self-assurance (six items), attentiveness (four items), and serenity } \\
\text { (three items). }\end{array}$ \\
\hline $\begin{array}{l}\text { Global Mood Scale } \\
\text { (GMS). (Denollet, } \\
\text { 1993) }\end{array}$ & $\begin{array}{l}\text { A } 20 \text {-item scale that measures two mood factors: positive affect (defined by ten items), and } \\
\text { negative affect (ten items). Participants respond to each item on a 5-point scale ranging from } \\
\text { "not at all" to "extremely", according to the extent to which they have experienced each mood } \\
\text { state. The GMS differs from the PANAS in conceptualizing negative affect as feelings of } \\
\text { malaise and exhaustion rather than anxiety and apprehension. }\end{array}$ \\
\hline $\begin{array}{l}\text { Profile of Mood States } \\
\text { (POMS). (McNair } \\
\text { et al., 1971). }\end{array}$ & $\begin{array}{l}\text { A } 65 \text {-item scale that measures six mood factors. Five of the scales measure negative mood states } \\
\text { (tension-anxiety; depression-dejection; anger-hostility; fatigue-inertia; confusion- } \\
\text { bewilderment), and one measures vigor-activity. Each item is an adjective or brief phrase that } \\
\text { describes a facet of mood state. Participants respond to each item on a 5-point scale ranging } \\
\text { from "not at all" to "extremely", according to how well it matches their own feelings. A brief } \\
\text { version (POMS brief) is also available that measures the same factors in } 30 \text { items. }\end{array}$ \\
\hline
\end{tabular}


and highlights the variety of ways in which mood states can be broken down into higherorder factors. In some cases, a number of singleitem measures of mood states may be grouped together to form a single tool. For instance, the Visual Analogue Mood Scale (VAMS; Stern et al., 1997) contains seven items that each measures a different aspect of mood ("sadness," "fear," "anger," "tiredness," "confusion," "happiness," and "energy"). However, unlike factor scales, participants' responses to each item in the VAMS are themselves treated as the unit of description rather than being combined to form a composite mood score.

Single-item measures and factor scales are associated with different considerations that affect their suitability for particular situations. Most evidently, single-item tools are shorter than their factor scales equivalents, making them quicker and less laborious for participants to complete. This makes them particularly well suited to study protocols that require multiple assessments to be completed, when working with easily fatigued participants, or when assessments are administered during everyday activities. Having fewer items in a scale also makes it easier for participants to remember how they responded on previous occasions, enabling participants to use their earlier responses as a benchmark against which to compare their current feelings. This can increase the testretest reliability of the measures, making them useful for investigating patterns of mood state over time.

Single-item measures also confer a higher degree of transparency of their content than do factor scales. That is, for instance, a single-item measure of "happiness" will comprise a single question that literally asks about happiness. In contrast, a factor scale of happiness would comprise a set of composite items that collectively describe the term "happiness". The contents of the items cannot be determined by the factor name alone, and factors from different tests that have the same name might actually contain quite disparate items. An example of this is seen with two factor scales that each measure "negative affect" - the Positive and Negative Affect Schedule (PANAS; Watson et al., 1988) and the Global Mood Scale (GMS; Denollet, 1993) - but which define it in different ways. In the PANAS, negative affect is conceptualized as "anxious apprehension," and is defined by terms such as "scared," "upset," "afraid," and "distressed". However, in the GMS negative affect is conceptualized as "emotional exhaustion," and is defined by terms such as "weary," "fatigued," "tired," and "feeble". Thus, while scores on the positive affect scales of the two tools correlate highly, the negative affect items of each of the two measures appear to represent quite different aspects of negative mood (Denollet and De Vries, 2006). When using or interpreting data from factor scales researchers should therefore ensure that they are familiar with the content of the items underlying each factor, and that they correspond well to the mood construct of interest in the research.

Of course, transparency between the name and content of a single-item measure does not necessarily mean that a participant's understanding of the item will correspond to that of the researcher. As discussed previously, lay definitions of mood terms may well differ between people. Factor scales offer more robustness against such differences of interpretation. For one thing, mood factor scores are defined by participants' responses to several related terms rather than just one item. A misunderstanding of any one item will therefore have a much smaller impact on the validity of the composite score than it would in a single-item scale. Secondly, items whose meaning is understood differently by some people can be identified by examining the degree of response consistency between the items that make up each factor, and then removed from the scale. Thus, a high level of internal consistency within a scale provides psychometric evidence that individual items are being understood in the same way by different people, and are tapping into the same construct. Researchers who choose to use single item measures to assess mood are therefore advised to ensure that a high level of convergent validity has been established against a reliable factor scale.

\section{Depression scales}

Clinical tools for assessing depression typically include items that ask participants to rate the extent to which they have recently experienced mood states such as sadness, depressed mood, and happiness. Scores on clinical depression scales have been shown to correlate well with scores on self-reported mood scales (Watson et al., 1988; Denollet and De Vries, 2006). This suggests that measures developed to identify clinical depression are able to capture aspects of normal mood state. However, their applicability to non-clinical populations is limited for a number of reasons. First, rather than capturing a comprehensive picture of normal mood states, depression scales have been developed to detect or quantify those aspects of mood that are most reliably associated with a depressive disorder. Accordingly, scores from nonclinical populations are skewed toward the lower end of the range, and fall within a relatively narrow distribution (Crawford et al., 2009). This reduces 
Table 3. Details of the content of some self-report clinical scales used for assessing depression

\begin{tabular}{ll}
\hline SCALE & DESCRIPTION OF CONTENT \\
$\begin{array}{l}\text { Geriatric Depression } \\
\begin{array}{l}\text { Scale (Yesavage } \text { et al., } \\
\text { 1983) }\end{array}\end{array}$ & $\begin{array}{l}\text { Contains items relating to depressed mood, happiness, helplessness, hopelessness, boredom, } \\
\text { self-worth, hopes and fears for the future, life satisfaction, activities and interests, agitation, } \\
\text { energy levels and motivation, and thinking and memory. }\end{array}$ \\
$\begin{array}{l}\text { CES-D (Radloff, 1977) } \\
\text { Contains items related to depressed mood, happiness, pleasure, appetite, self-worth, evaluations } \\
\text { of life, motivation, concentration, fears for the future, social interactions, and perceptions of } \\
\text { others' feelings about them. }\end{array}$ \\
$\begin{array}{l}\text { Contains items relating to depressed mood, enjoyment, irritability, appetite, sleep patterns, } \\
\text { Concentration, decision-making, fatigue, weight loss, constipation, heart rate, agitation, } \\
\text { (Zung, 1965) }\end{array}$ & \begin{tabular}{l} 
activities, and self-worth. \\
\hline
\end{tabular}
\end{tabular}

their sensitivity to between-group differences in mood state, or changes in mood state over time. Second, many items in clinical depression scales do not directly relate to participants' affective mood experiences, and instead address some of the nonaffective symptoms of depression, such as problems with sleep, appetite, and cognition (see Table 3). This limits the specificity of depression scales as general measures of mood state. Rather than being used as measures of normal mood state, clinical depression scales are therefore better viewed as an ideal means for identifying cases of depression, or the presence of depressive symptoms, in nonclinical samples of participants.

\section{Temporal perspectives in mood assessment}

Alongside mood constructs, another key element in mood assessment is the temporal perspective that participants are asked to take when reporting their mood. Measures can generally be described as assessing mood either retrospectively or contemporaneously to the participant's experience. In retrospective mood assessment, participants are asked to think back and report the moods that they experienced over a recent period of time, for instance the previous day or week. In contemporaneous mood assessment (sometimes called ecological momentary assessment or experience sampling method), participants report how they feel at that particular moment in time. For many assessment scales, (e.g. McNair et al., 1971; Watson and Clark, 1994; Stern et al., 1997) either retrospective or contemporaneous instructions can be applied to the same items, allowing the researcher some flexibility in terms of the temporal perspective that they take. It is therefore important to be aware that the two temporal perspectives of assessment differ in terms of (i) the psychological processes that they utilize and (ii) the aspects of mood experience that they capture. The suitability of each perspective therefore differs according to the nature of the research question being addressed.

\section{Retrospective assessment}

Retrospective mood assessments require participants to retrieve and report information about their prior mood states from memory. Usually they are asked to summarize the moods that they experienced during a specific period of time, such as the previous day or week. Some participants, particularly those with memory impairments, may be unable to consciously recollect their recent activities or moods, making retrospective assessment unfeasible. However, even for participants who feel that they can accurately recall their recent mood states, their reported moods are likely to differ from the moods that they actually experienced in a number of ways. For example, it is known that both the most recent and the most extreme feelings that were experienced within the time period of interest skew retrospective reports of mood (Redelmeier and Kahneman, 1996). These are also affected by the mood that the participant is in at the time that they make their assessment (Schwartz and Clore, 1983). Retrospective mood ratings can also be influenced by participants' own theories of how they are likely to have felt during a given period of time. For instance, if a participant believes that they generally feel less happy on a Monday than a Sunday, they are more likely to misremember their mood for any particular Monday as being more negative than it actually was (Areni and Burger, 2008). This difference between moods that occurred and the way that they are subsequently represented in memory has been termed the "memory-experience gap" (MironShatz et al., 2009).

The existence of the memory-experience gap limits the accuracy with which retrospective methods are able to capture actual mood state experiences. Nevertheless, retrospective methods do seem to access important information about the representations of mood state that individuals use when reviewing past experiences or making decisions about the future. For instance, Wirtz et al. (2003) showed that participants' retrospective 
ratings of the moods they experienced during a holiday were better predictors of their desire to repeat the holiday than were actual ratings of mood taken during the holiday. Thus, information about how we believe we felt during a specific period or activity may sometimes be more important than how we actually did feel at the time. Retrospective assessments of mood may therefore be more useful than contemporaneous methods when addressing research questions concerned with participants' conscious recollections of their past mood experiences, or when trying to predict their future behavior.

\section{Contemporaneous assessment}

Contemporaneous measures require participants to report on how they are feeling at the moment of reporting. They therefore provide a snapshot of a participant's mood at any particular time. The absence of memory demands in contemporaneous assessment methods means that distortions associated with forgetting or recall bias are less likely to occur than in retrospective measurement. The time at which particular mood experiences are sampled can also be accurately recorded (Stone and Shiffman, 2002). Together, these characteristics make contemporaneous methods ideally suited to addressing questions about the temporal correlations between mood states and other variables or events of interest, such as heart rate, eating patterns, or exercise behavior.

Scores from contemporaneous assessment methods are also easier to interpret than those taken from retrospective assessments, which require participants to summarize their feelings over a period of time. A retrospective daily rating of, for instance, 5/10 for happiness could be interpreted as either (1) a period of time in which a constant level of average mood was experienced, or (2) a period characterized by both very high and very low levels of happiness. Scores from contemporaneous assessments relate to just one point in time: how they feel right now, and therefore avoid the ambiguity of an average score.

One major limitation of contemporaneous methods is that they only capture mood states that happen to coincide with a point in the sampling schedule. While this is ideal for studies examining the precise temporal characteristics of mood state, it presents a challenge when trying to capture a more general picture of a person's mood state over a longer period of time: important mood states occurring outside of the sampling schedule can be missed from the data collection, and the mood states that are captured may be unrepresentative of the participant's typical mood experiences. Contemporaneous methods are therefore limited in their utility for capturing data that can be generalized to periods beyond the particular time points sampled.

\section{Day reconstruction method}

The Day Reconstruction Method (DRM; Kahneman et al., 2004) is a relatively new method of retrospective mood assessment that is believed to reduce the distortions associated with memory recall in order to collect data akin to that of contemporaneous assessment (Miron-Shatz et al., 2009). In DRM, participants are first required to reconstruct an ordered list of their previous day's activities, detailing the start and end point of each discrete "episode" of activities that occurred. For instance, the first episode might be "getting up," followed by "eating breakfast," and then "going for a walk". Participants are also required to indicate the type(s) of activity undertaken in each episode (shopping, socializing, eating, etc.), the location of the activity, and any other people who were involved. Once this diary is complete, participants use a set of Likert-type scales to retrospectively report the moods that they experienced in each episode. The process of systematically reconstructing the day's events is believed to minimize forgetting and recall bias during the subsequent mood rating exercise, thereby improving the validity of participants' reports. The DRM procedure also allows information about diurnal patters of mood state to be collected in a manner that is less likely than contemporaneous methods to interfere with participants' everyday activities, and ensures that important mood states are less likely to be missed from the data collection. DRM may therefore be particularly useful when details about the average mood states experienced during several periods of the day are required.

DRM data collected from middle-aged participants has revealed diurnal patterns of mood that are similar to those collected through contemporaneous assessment, suggesting that the procedure does help participants to accurately recall their prior mood states (Kahneman et al., 2004). However, contemporaneous assessment and DRM from the same participants and covering the same periods of time have not yet been directly compared, and so the extent to which DRM data actually do reflect participants' real-time mood experiences has not been determined. Indeed, it is possible that the DRM diary procedure itself may lead to additional distortions or biases in mood 
recall (White and Dolan, 2009). The suitability of the method for use with older populations has also not yet been thoroughly examined. In particular, while the DRM procedure appears to be well tolerated by relatively well-educated, highfunctioning older adults (Parisi, 2010), levels of accuracy, and compliance in more impaired older participants still needs to be established.

A further limitation of DRM stems from the fact that the duration over which mood states are summarized is determined by the number and duration of daily episodes reported by the individual. This varies considerably across individuals, with some participants identifying just one episode of activities in a day (Miron-Shatz et al., 2009). Variations in mood state that occur within any particular activity will therefore not be detected, and it can be difficult to compare mood patterns across participants or periods of time that differ in terms of the number of discrete episodes reported. This is particularly important when working with older populations who are housebound, isolated, or who engage in few activities throughout the day, and whose days may comprise fewer discrete episodes compared to more active engaged individuals.

In sum, DRM offers a promising addition to the mood assessment arsenal, which offers improved recall of consecutive mood states without the burden and selectivity associated with contemporaneous assessment. However, further work is required to establish the reliability and acceptability of this method for older and more cognitively impaired populations. It is not yet clear whether data collected using DRM more closely reflect mood states that were actually experienced, as in contemporaneous assessments, or the posthoc reconstructions of these experiences that are captured in other retrospective methods. Finally, while the developers of DRM have suggested the method could be used for more distant periods of time than the previous day (Kahneman et al., 2004), its suitability for such situations has not yet been explored.

\section{Summary and general recommendations}

The selection of tools and methods to assess mood state in older populations has important implications for the interpretation of data collected. Practical issues relating to the burden and complexity of the methods will also impact on the reliability of the data collected. No single method of mood assessment can be considered to be superior in all situations. Rather, the suitability of a tool is dependent on the nature of the research question, the design of the study, and the population being assessed. For example, a study aiming to measure the immediate effects of particular foodstuffs on mood state will warrant very different methods compared to a study investigating the general impact of food poverty on subjective well-being. A thorough understanding of the issues and considerations outlined in this review is therefore essential when either selecting tools for use in mood assessment research or when critically evaluating the results of geriatric mood research.

In selecting measures for mood research, it is important to bear in mind that older adults tend to report higher levels of positive affect and life satisfaction than younger adults. This should make it easier to identify people who are experiencing difficulties as they can be expected to report lower levels of happiness and satisfaction than their peers. However, some researchers have suggested that high levels of satisfaction and positivity in older age reflect a tendency to minimize negative experiences by regulating emotional responses (Gross and Levenson, 1993). By focusing internally on their mood, older adults may tune out external information (Mienaltowski and Blanchard-Fields, 2005). This may lead to them not picking up on or processing important details when in a negative mood. For example, a person who is given a serious medical diagnosis may need extra time to take in and come to terms with the information, before they can process details of how to manage their new medication or other interventions. Developing more sensitive and appropriate measures of mood in older age that distinguish subtle changes, which may not occur in younger age groups, is vital if we are to support the increasing numbers of older adults so that they may live and age as well as possible.

Clear and frank discussion of issues such as these relating to mood assessment in older adults is also essential for optimizing and advancing research in this field. Following the proposed guidelines of Stone and Shiffman (2002) for reporting contemporaneous mood assessment procedures, we advocate that better communication of the rationale for using a particular method, as well as details about the amount of participant training required, the frequency and nature of completion errors, and any issues with compliance that were observed, should be reported as standard in all geriatric mood research reports. This would encourage a more thoughtful and individualistic approach to the selection and modification of mood assessment tools when designing research studies. It would also assist readers in their appraisal and interpretation of mood assessment data, and promote efforts to improve upon existing tools for future research. 


\section{Conflict of interest}

None.

\section{Description of authors' roles}

Laura Brown reviewed the literature, developed the concept and structure of the paper, and prepared and edited all sections of the paper. Arlene Astell contributed to the conceptualization, content, drafting, and editing of all sections of the paper and completed the revisions.

\section{Acknowledgments}

This work was supported by grant number RES354-25-0003 awarded to Arlene Astell from the New Dynamics of Ageing (NDA) Programme. The funding partners of the NDA are: Economic and Social Research Council (ESRC), Engineering and Physical Sciences Research Council (EPSRC), Biotechnology and Biological Sciences Research Council (BBSRC), Medical Research Council (MRC), and Arts and Humanities Research Council.

\section{References}

Abdel-Khalek, A. M. (2006). Measuring happiness with a single-item scale. Social Behavior and Personality, 34, 139-150.

Areni, C. S. and Burger, M. (2008). Memories of "bad" days are more biased than memories of "good" days: past Saturdays vary, but past Mondays are always blue. Fournal of Applied Social Psychology, 38, 1395-1415.

Beedie, C., Terry, P. and Lane, A. (2005). Distinctions between emotion and mood. Cognition and Emotion, 19, 847-878. doi:10.1080/02699930541000057.

Beedie, C., Terry, P. and Lane, A. (2011). Differential assessment of emotions and moods: development and validation of the emotion and mood components of anxiety questionnaire. Personality and Individual Differences, 50, 228-233. doi:10.1016/j.paid.2010.09.034.

Charles, S. T. and Almeida, D. M. (2006). Daily reports of symptoms and negative affect: not all symptoms are the same. Psychology and Health, 21, 1-17. doi:10.1080/14768320500129239.

Costa, P. T. Jr., McCrae, R. R. and Zonderman, A. B. (1987). Environmental and dispositional influences on well-being: longitudinal follow-up of an American national sample. British fournal of Psychology, 178, 299-306.

Crawford, J. R. et al. (2009). A convenient method of obtaining percentile norms and accompanying interval estimates for self-report mood scales (DASS, DASS-21, HADS, PANAS, and sAD). British fournal of Clinical Psychology, 48, 163-180. doi:10.1348/014466508X377757.
Denollet, J. (1993). Emotional distress and fatigue in coronary heart disease: the Global Mood Scale (GMS). Psychological Medicine, 23, 111-121.

Denollet, J. and De Vries, J. (2006). Positive and negative affect within the realm of depression, stress and fatigue: the two-factor distress model of the Global Mood Scale (GMS). Fournal of Affective Disorders, 91, 171-180. doi:10.1016/j.jad.2005.12.044.

Diener, E. (2000). Subjective well-being: the science of happiness and a proposal for a national index. American Psychologist, 55, 34-43. doi:10.1037//0003-066X.55.1.3.

Fischer, J. A. (2009). Happiness and age cycles - return to start. . ? On the functional relationship between subjective well-being and age. OECD Social, Employment and Migration Working Papers, No. 99, OECD Publishing. Available at: http://dx.doi.org/10.1787/220573570724.

Fliege, H., Becker, J., Walter, O. B., Bjorner, J. B., Klapp, B. F. and Rose, M. (2005). Development of a computer-adaptive test for depression (D-CAT). Quality of Life Research, 14, 2277-2291.

Gardner, W. et al. (2004). Computerized adaptive measurement of depression: a simulation study. $B M C$ Psychiatry, 4, 13.

Gross, J. J. and Levenson, R. W. (1993). Emotional suppression: physiology, self-report, and expressive behavior. Fournal of Personality and Social Psychology, 64, 970-986.

Hill, R. D., van Boxtel, M. P. J., Ponds, R., Houx, P. J. and Jolles, J. (2005). Positive affect and its relationship to free recall memory performance in a sample of older Dutch adults from the Maastricht Aging Study. International Fournal of Geriatric Psychiatry, 20, 429-435. doi:10.1002/gps.1300.

Kahneman, D., Krueger, A. B., Schkade, D. A., Schwartz, N. and Stone, A. A. (2004). A survey method for characterizing daily life experience: the Day Reconstruction Method. Science, 306, 1776-1780. doi: 10.1126/science.1103572.

Kelley-Gillespie, N. (2009). An integrated conceptual model of quality of life for older adults based on a synthesis of the literature. Applied Research in Quality of Life, 4, 259-282. doi: $10.1007 /$ s1 1482-009-9075-9.

Konttinen, H., Silventoinen, K., Sarlio-Lähteenkorva, S., Männistö, S. and Haukkala, A. (2010). Emotional eating and physical activity self-efficacy as pathways in the association between depressive symptoms and adiposity indicators. American fournal of Clinical Nutrition, 92, 1031-1039. doi:10.3945/ajcn.2010.29732.

Larsen, J. T., McGraw, A. P. and Cacioppo. (2001). Can people feel happy and sad at the same time? fournal of Personality and Social Psychology, 81, 684-696. doi:10.1037//0022-3514.81.4.684.

Linley, P. A., Maltby, J., Wood, A. M., Osborne, G. and Hurling, R. (2009). Measuring happiness: the higher order factor structure of subjective and psychological well-being measures. Personality and Individual Differences, 47, 878-884. doi: 10.1016/j.paid.2009.07.010.

Lykken, D. and Tellegen, A. (1996). Happiness is a stochastic phenomenon. Psychological Science, 7, 186-189.

McNair, D. M., Lorr, M. and Droppleman, L. F. (1971). Manual for the Profile of Mood States. San Diego, CA: Educational and Industrial Testing Services. 
Mienaltowski, A. and Blanchard-Fields, F. (2005). Differential effects of mood on age differences in the correspondence bias. Psychology and Aging, 20, 589-600.

Miron-Shatz, T., Stone, A. and Kahneman, D. (2009). Memories of yesterday's emotions: does the valence of experience affect the memory-experience gap? Emotion, 9, 885-891. doi:10.1037/a0017823.

Parisi, J. M. (2010). Engagement in adulthood: perceptions and participation in daily activities. Activities, Adaptation, and Aging, 34, 1-16.

Petersen, C. (2006). A Primer in Positive Psychology. Oxford: Oxford University Press.

Powell, R. et al. (2009). Activity and affect: repeated within-participant assessment in people after joint replacement surgery. Rehabilitation Psychology, 54, 83-90. doi:10.1037/a0014864.

Radloff, L. S. (1977). The CES-D scale: a self-report depression scale for research in the general population. Applied Psychological Measurement, 1, 385-401. doi:10.1177/014662167700100306.

Redelmeier, D. A. and Kahneman, D. (1996). Patients' memories of painful medical treatments: real-time and retrospective evaluations of two minimally invasive procedures. Pain, 66, 3-8.

Robertson, C. et al. (2009). Meaning behind measurement: self-comparisons affect responses to health-related quality of life questionnaires. Quality of Life Research, 18, 221-230. doi:10.1007/s11136-008-9435-1.

Röcke, C., Li, S.-C. and Smith, J. (2009). Intraindividual variability in positive and negative affect over 45 days: do older adults fluctuate less than young adults? Psychology and Aging, 24, 863-878.

Ryan, M. R. and Deci, E. L. (2001). On happiness and human potentials: a review of research on hedonic and eudaimonic well-being. Annual Review of Psychology, 52, 141-166.

Ryff, C. D. (1995). Psychological well-being in adult life. Current Directions in Psychological Science, 4, 99-104.

Ryff, C. D. and Keyes, C. L. M. (1995). The structure of well-being revisited. Fournal of Personality and Social Psychology, 69, 719-727.

Schwartz, N. and Clore, G. L. (1983). Mood, misattribution, and judgments of well-being: informative and directive functions of affective states. Fournal of Personality and Social Psychology, 45, 513-523.

Stawski, R. S., Sliwinski, M. J., Almeida, D. M. and Smyth, J. M. (2008). Reported exposure and emotional reactivity to daily stressors: the roles of adult-age and global perceived stress. Psychology and Aging, 23, 52-61.

Steptoe, A. and Wardle, J. (2005). Positive affect and biological function in everyday life. Neurobiology of Aging, 26, S108-S112. doi:10.1016/j.neurobiolaging. 2005.08.016.

Stern, R. A., Arruda, J. E., Hooper, C. R., Wolfner, G. D. and Morey, C. E. (1997). Visual analogue mood scales to measure internal mood state in neurologically impaired patients: descrption and initial validity evidence. Aphasiology, 11, 59-70. doi:10.1080/02687039708248455.

Stone, A. A. and Shiffman, S. (2002). Capturing momentary, self-report data: a proposal for reporting guidelines. Annals of Behavioral Medicine, 24, 236-243.

Sunderland, T. et al. (1988). A new scale for the assessment of depressed mood in demented patients. American fournal of Psychiatry, 145, 955-959

Tennant, R. et al. (2007). The Warwick-Edinburgh Mental Well-being Scale (WEMWBS): development and UK validation. Health and Quality of Life Outcomes, 5, 63. doi:10.1186/1477-7525-5-63.

Urry, H. L. et al. (2004). Making a life worth living: neural correlates of well-being. Psychological Science, 15, 367-372.

Watson, D. and Clark, L. A. (1994). The PANAS-X: Manual for the Positive and Negative Affect Schedule - Expanded Form. Iowa City: University of Iowa.

Watson, D. and Clark, L. A. (1997). Measurement and mismeasurement of mood: recurrent and emergent issues. Fournal of Personality Assessment, 68, 267-296.

Watson, D. and Tellegen, A. (1985). Toward a consensual structure of mood. Psychological Bulletin, 98, 219-235.

Watson, D., Clark, L. A. and Tellegen, A. (1988). Development and validation of brief measures of positive and negative affect: the PANAS scales. Fournal of Personality and Social Psychology, 54, 1063-1070.

White, M. P. and Dolan, P. (2009). Accounting for the richness of daily activities. Psychological Science, 20, 1000-1008.

Wirtz, D., Kruger, J., Napa Scollon, C. and Diener, E. (2003). What to do on spring break? The role of predicted, on-line, and remembered experience in future choice. Psychological Science, 14, 520-524. doi:10.1111/1467-9280.03455.

Yesavage, A. et al. (1983). Development and validation of a geriatric depression screening scale: a preliminary report. Fournal of Psychiatric Research, 17, 37-49.

Zung, W. W. K. (1965). A self-rating depression scale. Archives of General Psychiatry, 12, 63-70. 